\title{
Evitação do dolo por dirigentes de empresas nos delitos relacionados à atividade empresarial*
}

\section{Dolus avoidance by managers in corporate crimes}

\section{Thomas Rönnau}

\section{Christian Becker}

Resumo: Na maioria dos delitos relacionados a empresas, os dirigentes não estão diretamente envolvidos na realização do tipo penal. Não obstante, eles podem ser responsabilizados por omissão, quando deixarem de tomar medidas necessárias para impedir a prática dos crimes cometidos por seus subordinados. Para isso, é preciso que tenham atuado com dolo, ao menos eventual. Neste artigo, os autores examinam os pressupostos de imputação subjetiva nos crimes omissivos impróprios praticados por dirigentes de empresas em relação aos fatos realizados por seus subordinados. Para tanto, após examinar os pressupostos jurídico-materiais do dolo, destacam especialmente as exigências para a sua determinação processual. Ao fim, descrevem a responsabilidade contraordenacional das pessoas jurídicas pela omissão no controle de atos ilícitos dos empregados, uma responsabilidade que independe do dolo dos dirigentes.

Palavras-chave: criminalidade de empresa; responsabilidade penal de diretores; crimes omissivos impróprios; dolo; sistemas de conformidade.

Abstract: In most of the corporate crimes, the managers are not directly involved in carrying out the criminal offense. However, they can be held responsible for omission, when they fail to take the necessary measures to prevent the criminal conducts committed by their subordinates. To establish that responsibility, they must have acted with criminal intent (dolus directus) or at least with dolus eventualis. In this article, the authors examine the conditions of mens rea in criminal omissions by company directors regarding facts carried out by their subordinates. After examining the legal definition of criminal intent, they especially highlight the requirements for its procedural determination. Finally, they

\footnotetext{
* Publicação original: RÖNNAU, Thomas; BECKER, Christian. Vorsatzvermeidung durch Unternehmensleiter bei betriebsbezogenen Straftaten. Neue Zeitschrift für Strafrecht, [s.I.], p. 569-575, 2016. Tradução de Marcelo Costenaro Cavali.
} 
describe the administrative liability of legal entities for the failure to control illegal acts of employees, a responsibility that does not depend on the intent of the managers.

Keywords: corporate crimes; criminal liability of corporate managers; criminal omissions; dolus; compliance programs.

Sumário: Introdução; 10 s pressupostos jurídico-materiais do conceito de dolo; 1.1 Fundamentos; 1.2 Dolo como fato psicológico (interno); 2 A determinação processual do dolo; 2.1 Ponto de partida; 2.20 elemento cognitivo do dolo; 2.30 componente volitivo; 3 Responsabilidade de acordo com 0 \$130 0WiG; Conclusão; Referências.

\section{Introdução}

Ocorrendo o cometimento de delitos em uma empresa, que se encontrem em conexão interna com sua atividade empresarial ou seu tipo de empreendimento (os chamados delitos relacionados à empresa) ${ }^{1}$, não existe, na maioria das vezes, um comportamento típico imediato por parte dos membros da direção da empresa ou, de todo modo, não é possível prová-lo. Assim ocorre, por exemplo, com os pagamentos de propinas, um fenômeno tipicamente levado a cabo, em empresas organizadas sob a forma de sociedade por ações, no nível de gerência intermediário².

No curso do chamado "caso de liberação de gases poluentes da VW", cujos inquéritos penais ainda estão no início ${ }^{3}$, os membros do conselho de administração não estavam diretamente envolvidos, até onde se sabe, no desenvolvimento do software que diminuía temporariamente os níveis de emissão de poluentes durante a realização dos testes regulatórios ${ }^{4}$. Se, em tais condições, é possível uma responsabilidade penal para além do nível hierárquico diretamente envolvido (empregados do departamento de vendas, engenheiros, etc.), de modo a atingir também os gestores da empresa, é algo que dependerá decisivamente da medida do conhecimento dos dirigentes sobre os comportamentos delitivos de seus subordinados $^{5}$. Se esse for o caso, não se considera apenas a participação ativa no

1 Para o conceito de delitos relacionados à empresa, cf. BGHSt 57, 42 = NJW 2012, 1237 (1238); para aprofundamento, ver BÜLTE, Vorgesetztenverantwortlichkeit im Strafrecht, p. 154 e ss.; SCHALL, FS-Kühl, p. 426 ss., com outras referências.

2 RÖNNAU, FS-Tiedemann, p. 713.

3 Primeiras reflexões sobre essa questão em ISFEN, JA 2016, p. 1 s., concluindo que uma punibilidade por estelionato poderia ser "considerada"; sobre a possível sonegação fiscal relacionada com a concessão de isenções fiscais por meio da declaração incorreta da classe de poluentes, cf. HEß, wistra 2016, p. 212 e ss.

5 WELLER, ZGR 45, p. 386, que descreve o conhecimento do acusado como o "ponto central de toda pena". 
delito relacionado à empresa dos empregados em questão, mas também, independentemente de uma ação comissiva, da punibilidade por omissão, por força, ao menos em princípio, da predominantemente reconhecida responsabilidade dos dirigentes de empresa por omissão (Geschäftsherrenhaftung) ${ }^{7}$.

Neste contexto, pode-se deparar com o fenômeno da chamada "cegueira deliberada" ${ }^{8}$, quando o desconhecimento do dirigente empresarial não tiver por base comportamentos conspiratórios dos empregados criminosos, mas, sim, o fato de os membros dos escalões mais altos não quererem tomar conhecimento de processos criminosos evidentes em curso na empresa, ignorando, portanto, os sinais e bloqueando as respectivas informações ("bad news doesn't flow upstream" $\left.^{\prime \prime}\right)^{9}$. Mesmo que seja possível imputar o conhecimento à empresa, sob certas condições ${ }^{10}$, no caso de ignorância contrária ao dever, a exigência de dolo inviabiliza, geralmente, uma fundamentação da responsabilidade penal individual. Esse resultado é particularmente questionável do ponto de vista político-criminal ali onde o dirigente, em um primeiro momento, formula metas que claramente não são atingíveis sem violação à lei, para, em um segundo momento, alegar ignorância dos crimes quando eles são efetivamente cometidos. Pense-se, por exemplo (no âmbito do direito das contraordenações), nas regulamentações sobre quantidades de cargas e prazos de entrega em uma empresa de transportes, que são praticamente inviáveis de serem atendidos sem sobrecarga ou sem a desconsideração dos períodos de descanso prescritos para os empregados ${ }^{11}$.

Sobre os diferentes tipos de participação ativa, cf. ROTSCH, Criminal Compliance, $\S 4 \mathrm{~nm}$. 4 e ss.: também ACHENBACH, Handbuch Wirtschaftsstrafecht, I 3, nm. 24 e ss.

7 Visão geral em ROTSCH, Handbuch Wirtschaftsstrafecht, I 4 nm. 73 e s.; KK-OwiG-Rogall, § 130 nm. 2, cada qual com ulteriores indicações sobre o estado da discussão.

8 Sobre o contexto do Direito Penal Econômico, SCHEMMEL/KIRCH-HEIM, CCZ 1, p. 96 e s.; a respeito do Direito Penal Internacional, no âmbito do qual a cegueira deliberada desempenha um papel para a responsabilidade penal por crimes contra a humanidade, nos termos do art. 7 do Estatuto da CCI, cf. AMBOS, Internationales Strafrecht, $\S 7$, nm. 198; BÜLTE, ob. cit. (nota 1), p. 566 e ss.; sobre o Direito norte-americano, cf. LUBAN, Georgetown Law Journal 87, p. 957 e ss., que fala principalmente de "ignorância deliberada"; MARCUS, Yale Law Journal 102, p. 2231 e ss., cada qual com ulteriores indicações sobre o estado da discussão.

$9 \quad$ LUBAN, ob. cit. (nota 8), p. 958.

10 BUCK-HEEB, Corporate Compliance, §2 nm. 23 e ss.; sobre a imputação do conhecimento no âmbito empresarial, cf. recentemente WELLER, ob. cit. (nota 5), p. 396 ess.; completo, cf. SPINDLER, Unternehmensorganisationspflichten, p. 610 ss. e p. 963 ss.

11 Punível como contraordenação de acordo com os $\S 334,69 a$ (3) nº 4 StVZO (Straßenverkehrs-Zulassungs-Ordnung, Regulamento de Licenciamento do Trânsito), §24 StVG (Straßenverkehrsgesetz, Lei de Tráfego Rodoviário) e §8 FPersG (Gesetz über das Fahrpersonal von Kraftfahrzeugen und Straßenbahnen, Lei sobre Motoristas de Automóveis e Bondes), em conjunto com o art. 6 AETR (Convenção Europeia sobre o trabalho dos empregados do setor de transportes internacionais). 
Em conexão com o "caso do escândalo do diesel da VW" - especialmente com vistas à promoção de vendas de automóveis no mercado dos EUA -, a construção de motores a diesel novos e rentáveis, mas, ao mesmo tempo, ecológicos, econômicos e poderosos, chega a ser visivelmente uma "quadratura do círculo". $\mathrm{O}$ fato de esse objetivo ter sido alcançado deveria ter deixado os dirigentes pelo menos desconfiados. Se sabiam mais sobre os meios de resolução dessa complicada equação é algo que ainda não se sabe ${ }^{12}$.

Se, porém, um desconhecimento baseado na indiferença e/ou na leviandade (culpa grave) exclui a existência do dolo é algo que não depende apenas dos pressupostos jurídico-materiais do dolo eventual (ver, a seguir, Seção 1). Pelo contrário, deve-se ter em mente especialmente as exigências para a sua determinação processual (Seção 2). Finalmente, é necessário traçar as linhas da responsabilidade contraordenacional de acordo com o §130 OWiG (Gesetz über Ordnungswidrigkeiten, Lei de Contraordenações), uma responsabilidade que independe do dolo dos dirigentes (Seção 3).

\section{0 pressupostos jurídico-materiais do conceito de dolo}

\subsection{Fundamentos}

O dolo - assim como muitos outros conceitos centrais da teoria geral do delito - não está definido em lei ${ }^{13}$. Do disposto no §16 I 1 StGB (Strafgesetzbuch, Código Penal alemão) decorre, em uma interpretação a contrario sensu, que o conhecimento das circunstâncias que pertencem ao tipo legal é um elemento necessário do dolo ${ }^{14}$. Assim, a lei nomeia como objeto do dolo, um tanto ambiguamente, as circunstâncias a serem subsumidas ao tipo legal e que são, na maioria das vezes, de natureza fática, mas que têm também, por vezes, caráter valorativo (normativo) ${ }^{15}$. Além disso, reconhece-se que existem três diferentes formas de dolo: o dolo direto, que se subdivide, de um lado, em intenção, isto é, a busca proposital da realização do fato típico como objetivo final ou intermediário, e, de outro lado, em conhecimento, o conhecimento seguro da ocorrência das circunstâncias fáticas ${ }^{16}$. Como condutas praticadas com dolo direto não estarão,

12 Compare-se a apresentação dos fatos do caso em ISFEN, ob. cit. (nota 3), p. 1 e s.

13 RISSING-VAN SAAN, FS-Geppert, p. 499.

14 LKStGB-Vogel, $\$ 15 \mathrm{~nm} .73$.

15 MüKoStGB-Joecks, §16 nm. 7 com outras referências; LKStGB-Vogel, §15 nm. 28.

16 Por todos, RÖNNAU, JuS 50, p. 677; aprofundado, SAMSON, JA 1989, p. 449 e ss. 
em regra, presentes no nosso contexto, o dolo eventual (Eventualvorsatz), muitas vezes mal compreendido como dolo condicional (bedingter Vorsatz), torna-se o centro das atenções ${ }^{17}$. Os seus pressupostos são objeto de uma contínua controvérsia, cuja importância se deve principalmente à distinção em relação à imprudência, muitas vezes impune ${ }^{18}$. Sem prejuízo de certa convergência entre as posições contrárias ${ }^{19}$, contesta-se a existência de um elemento volitivo que vá além do conhecimento no sentido do §16 I 1 StGB (o chamado elemento intelectual ou cognitivo do dolo), bem como o conteúdo e a estrutura dos respectivos componentes ${ }^{20}$. O BGH (Bundesgerichtshof, Tribunal Federal alemão) acolhe em sua jurisprudência a teoria da "aprovação em sentido jurídico" (Billigung im Rechtsinne), segundo a qual o dolo eventual está presente quando o réu

reconhece a produção do resultado típico como possível e não inteiramente remota e põe-se de acordo com isso de maneira que tem uma assunção aprovadora da realização do tipo ou, em razão do objetivo perseguido, aceita que ele ocorra, ainda que a produção do resultado seja em si mesma indesejável; há culpa consciente, por outro lado, quando o agente não está de acordo com a realização do tipo reconhecida como possível, e confia seriamente - não apenas de modo vago - que o resultado não se produzirá ${ }^{21}$.

A jurisprudência coloca-se, assim, no campo das teorias volitivas, porque, ao lado da consideração como possível da realização do tipo (como elemento cognitivo do dolo), pressupõe um elemento volitivo ao exigir a "assunção aprovadora" (billingenden Inkaufnahme) ${ }^{22}$. Isso está, de fato, em consonância com a doutrina dominante, que reconhece o dolo eventual quando o agente conta seriamente com a possibilidade de realização do tipo (elemento cognitivo) e com ele se conforma (elemento volitivo), enquanto a culpa consciente é caracterizada

17 Sobre a imprecisão do conceito de "dolo condicionado", ver ROXIN, Strafrecht AT I, §12 nm. 24.

18 SCHÜNEMANN, FS-Hirsch, p. 364: "Praticamente a fronteira mais importante do Direito Penal"; SCHROTH, FS-Widmaier, p. 779 e s.

19 FRISCH, GS-Meyer, p. 539; HASSEMER, GS-Armin Kaufmann, p. 306; também PUPPE, ZStW 103, p. 1.

20 Para uma introdução ao estado da controvérsia, cf. ROXIN, ob. cit. (nota 17), §12 nm. 21 e ss.; comprovação exaustiva em HILLENKAMP, 32 Probleme aus dem Strafrecht AT, p. 1 e ss.

21 BGHSt 36, 1 = NJW 1989, 781 (783); fundamentos em BGHSt 7, 363 = NJW 1955, 1688, com mais comentários de Karl Engisch; mais recentemente BGH NStZ 2007, 700 (701).

22 Fundamentos em BGH NJW 1955, 1688 (1690); compare-se, porém, FRISCH, ob. cit. (nota 19), p. 538 e s., que atesta que o BGH abandonou a teoria do assentimento há muito tempo. 
pelo fato de que o autor, apesar da reconhecida possibilidade de realização do delito, confia seriamente na sua não ocorrência ${ }^{23}$.

\subsection{Dolo como fato psicológico (interno)}

Para esse ponto de partida das doutrinas volitivas dominantes e que não pode ser adequadamente examinado no presente artigo ${ }^{24}$, o dolo não é afastado somente quando um dirigente de empresa não contou com a possibilidade de que crimes fossem cometidos por seus subordinados, mas, além disso, quando reconhece essa possibilidade, porém, ao fim, confia seriamente que isso não chegaria a acontecer. O dolo deve, portanto - sem prejuízo do componente normativo inerente a todo conceito jurídico -, ser compreendido como um fato psicológico, como evento interno ${ }^{25}$. Assim, deve-se rejeitar uma abordagem estritamente normativa, segundo a qual o dolo, sob determinadas condições, poderia ser considerado apesar da falta de conhecimento. Essa construção tem sido defendida na doutrina jurídico-penal sobretudo por Jakobs, que parte da teoria do dolo indireto (dolus indirectus) ${ }^{26}$ e, dessa maneira, pretende compreender os casos de "indiferença diante dos fatos" (Tatsachengleichgültigkeit) - em última análise, uma espécie de cegueira deliberada (wilful blindness) - como atos dolosos ${ }^{27}$. Com algumas limitações, encontram-se tendências similares de normativização, embora menos abrangentes, também em alguns defensores de teorias cognitivas do

23 ROXIN, ob. cit. (nota 17), §12 nm. 21 e ss., em especial nm. 27; mais informações em HILLENKAMP, ob. cit. (nota 20), p. 9 e s.; sobre a ampla identidade dessa concepção com o conceito da jurisprudência, cf. FRISCH, ob. cit. (nota 19), p. 540.

24 Lúcido, por uma concepção cognitiva do dolo, cf. FRISCH, ob. cit. (nota 19), p. 536 e sS.; FRISCH, Vorsatz und Risiko, p. 473 e ss. (e passim); PUPPE, ob. cit. (nota 19), p. 9 e ss.; NKStGB-Puppe, $\$ 15$ nm. 64 e ss.; HERZBERG, JuS 26, p. 249 e ss.; por outro lado, para uma concepção volitiva, por exemplo, SCHROTH, Vorsatz als Aneignung der unrechtskonstituierenden Merkmale, p. 115 e ss.; SCHROTH, ob. cit. (nota 18), p. 783 e ss.; SCHÜNEMANN, ob. cit. (nota 18), p. 369 e s.; GAEDE, Strafgesetzbuch, $\$ 15$ nm. 21 e ss.; em complemento, também BUNG, Wissen und Wollen im Strafrecht, p. 265 e ss.

25 Mais profundamente sobre a relação entre aspectos psicológicos e normativos, cf. ROXIN, FS-Rudolphi, p. 243 e ss.; LKStGB-Vogel, $\$ 15$ nm. 64 e ss.; GAEDE, ZStW 121, p. 262 e ss.; cético, de outro lado, sobre a relevância dos fatores psicológicos, FISCHER, StGB, $\$ 15 \mathrm{~nm}$. 9; sobre a origem da concepção psicológica em Feuerbach, JAKOBS, ZStW 114, p. 588; PUPPE, ob. cit. (nota 19), p. 28 e ss., cada qual com ulteriores indicações.

26 De acordo com seu criador, Carpzov (1595-1666), o dolo do autor se estende também àquilo que se segue diretamente e per se ao fato ("quod inmediater et per se sequitur"). Quem, por exemplo, dolosamente perfura alguém com uma espada tem dolo indireto de matar, porque a sua vontade não se relaciona à perfuração, mas a tudo o que se segue como consequência imediata dela, mesmo que o autor não o deseje; sobre o tema, com informações sobre a fonte e tradução, cf. PUPPE, ob. cit. (nota 19), p. 24 e ss.

27 JAKOBS, ob. cit. (nota 25), p. 593 e ss.; demonstração de outras abordagens, principalmente por parte dos discípulos de Jakobs, em GAEDE, ob. cit. (nota 25), p. 248 e ss.; mais aprofundado e crítico sobre a abordagem de Jakobs a partir de uma perspectiva jurídico-filosófica, BUNG, ob. cit. (nota 24), p. 25 e ss. 
dolo ${ }^{28}$. De todo modo, em sua variante mais radical, que é a encontrada em Jakobs, a normativização do dolo tem sido consistentemente recusada. Ele defende essencialmente o seguinte: o dolo deve ser reconhecido independentemente de o autor refletir ou não sobre a realização do tipo, desde que o conhecimento das circunstâncias fáticas Ihe seja indiferente, no sentido de que seria irrelevante para sua decisão, isto é, de que o autor também teria agido ainda que tivesse conhecimento dos fatos. Isso porque, em tais casos, a exclusão da punição dolosa se mostra um privilégio injustificável, que tampouco seria exigido de lex lata: considerar a indiferença como dolo corresponde à regulação do erro de proibição do §17 2 StGB; o §16 I 1 StGB precisaria ser interpretado racionalmente, de modo que o desconhecimento irrelevante para a decisão não seja abrangido e também o $\$ 18$ StGB deveria ser limitado à realização do resultado por erro culposo ${ }^{29}$. A crítica aqui aponta, com razão, que essa abordagem significa, à luz do art. 103 II GG (Grundgesetz, Lei Fundamental alemã), uma redução teleológica contra o réu muito pouco justificável, a qual dificilmente pode explicar a existência de delitos qualificados pelo resultado (\$18 StGB) ${ }^{30}$, e que, além disso, em última instância, tende à punição de um dolo meramente hipotético ${ }^{31}$. No Direito Penal Internacional, afirma-se, ademais, que a abrangência da cegueira intencional no dolo configuraria uma violação do princípio da culpabilidade ${ }^{32}$.

De acordo, portanto, com a teoria volitiva do dolo psicologicamente orientada, sustentada pela opinião dominante, o dolo do dirigente de empresa é afastado quando ele não tenha reconhecido o risco de cometimento de crimes por subordinados ou, ao menos, quando haja confiado na não realização de um risco conhecido. Não importa se essa confiança pode ser reconduzida a mecanismos intrapsíquicos (repressão, controle de estresse) ou a medidas organizacionais para evitar a obtenção de informações comprometedoras. A reprovabilidade da falta de conhecimento ou da especial leviandade da confiança é irrelevante e só pode desempenhar um papel na realização de delitos culposos. A representação de um dirigente empresarial de que seus funcionários não cometem quaisquer infrações pode, portanto, justificar a exclusão do dolo, mesmo se for baseada na recusa em lidar com as ocorrências relevantes no sentido da doutrina da cegueira delibera-

SCHÜNEMANN, ob. cit. (nota 18), p. 365, fala de "limitada" e "totalmente pós-moderna objetivação".

29 JAKOBS, ob. cit. (nota 25), p. 593 e ss., 597 e s.

30 Parcialmente reconhecido por JAKOBS, ob. cit. (nota 25), p. 598.

31 Críticas concisas em VOGEL, GA 2006, p. 388 e s.; especificamente GAEDE, ob. cit. (nota 25), p. 262 e ss.; também KINDHÄUSER, FS-Eser, p. 345 e ss.; aprofundado, SCHÜNEMANN, ob. cit. (nota 18), p. 372 e s. 
da. Uma valoração diferente só pode ser feita se a decisão de "defesa" contra certas informações for, em última análise, já uma consequência do reconhecimento do crime como possível e do respectivo consentimento. Uma evitação intencional do dolo não pode existir conceitualmente, porque, quando alguém tem uma razão para propositalmente evitar o próprio dolo, ele já existe.

O conceito predominante de dolo psicologicamente fundado pode, porém, ter por consequência um aumento do risco jurídico-penal para os dirigentes empresariais que lidam escrupulosamente com uma iminente lesão a interesses de terceiros, enquanto a indiferença em relação aos fatos acaba desonerando-os de modo eficaz. Antes de, a partir disso, concluir por um argumento a favor de uma normativização mais forte do dolo ${ }^{33}$, deve-se ter em mente que a área problemática é significativamente reduzida na medida em que, ao lado dos critérios conceituais, leva-se em conta a determinação processual do dolo ${ }^{34}$.

\section{A determinação processual do dolo}

\subsection{Ponto de partida}

Ainda que o conceito de dolo, no sentido jurídico-material, seja essencialmente baseado em fatores psíquicos, uma normativização é, de todo modo, inevitável no contexto da prova processual, porque os fatos internos não são imediatamente acessíveis à observação ${ }^{35}$. Se o réu se cala ou nega ter tido consciência da realização do tipo, deve o juiz decidir, baseado em circunstâncias e indícios externos e no âmbito do livre convencimento judicial (cf. §261 StPO [Strafprozeßordnung, Código de Processo Penal alemão]), sobre a presença dos pressupostos psíquicos do dolo ${ }^{36}$. Embora os critérios jurídico-materiais do dolo na jurisprudência do BGH estejam cada vez mais consolidados e raramente sejam objeto de discussão profunda, a revisão dos julgados sobre a prova do dolo oferece um quadro díspar e rico ${ }^{37}$, no qual o ponto de cristalização é constante-

Assim JAKOBS, ob. cit. (nota 25), p. 588; parcialmente também PUPPE, ob. cit. (nota 19), p. 13 e s.

34 A respeito, GAEDE, ob. cit. (nota 25), p. 255 e ss.; para a diferenciação entre critérios jurídico-materiais e determinação processual do dolo, cf. FRISCH, ob. cit. (nota 19), p. 535 e s.; HILLENKAMP, GS-Armin Kaufmann, p. 360 e s.

35 LKStGB-Vogel, Vor $\$ 15$ nm. 71; SCHROTH, ob. cit. (nota 18), p. 780; PUPPE, ob. cit. (nota 19), p. 11.

36 V. somente MüKoStPO-Miebach, §261 nm. 126 com outras referências; RISSING-VAN SAAN, ob. cit. (nota 13), p. 502 e ss.; mais recentemente HRUSCHKA, FS-Kleinknecht, p. 194 e ss., que fala de uma atribuição do dolo fundada em circunstâncias externas; compare-se também SCHÜNEMANN, ob. cit. (nota 18), p. 367 e s.

Mais recentemente, sobre essa discrepância, VOLK, Münchener Anwaltshandbuch, §2 nm. 45 e ss. 
mente a questão do dolo eventual de matar nas condutas violentas especialmente perigosas ${ }^{38}$. $\mathrm{O}$ BGH exige aqui uma "visão geral de todas as circunstâncias fáticas objetivas e subjetivas do caso concreto, na qual devem ser abrangidos, acima de tudo, a periculosidade objetiva da ação, o modo concreto de ataque do agente, seu estado mental no momento do cometimento do fato e sua situação motivacional" ${ }^{39}$. Entretanto, há uma extensa casuística sobre a importância de diferentes espécies de indícios ${ }^{40}$. Particularmente obscuro neste contexto é o constantemente utilizado topos, crítico ao dolo, da inibição diante de homicídios, sobre cujo significado nem mesmo entre as distintas turmas de julgamento (Senaten) do $\mathrm{BGH}$ há uma clareza definitiva ${ }^{41}$. O critério da suposta inibição diante do homicídio provavelmente só pode ser aplicado, de modo convincente, como um entre vários indicadores que, no contexto da consideração geral requerida, em última análise, não tem nenhuma importância proeminente ${ }^{42}$.

É claro que essa jurisprudência, gerada em conexão com os $§ \S 211$ e 212 StGB, não pode ser aplicada diretamente às constelações de casos aqui tratadas ${ }^{43}$. No contexto do tipo subjetivo, os entendimentos dogmáticos apresentados no âmbito do Direito Penal Econômico discutem, sobretudo, questões de erro sobre elementos normativos do tipo e tipos penais em branco, ao passo que, do ponto de vista da dogmática geral do dolo, raramente são discutidas essas especificidades $^{44}$. Com efeito, a jurisprudência relacionada à norma da infidelidade patrimonial (\$266 StGB) sempre estabeleceu exigências particularmente rigorosas para a prova do dolo, especialmente quando se trata apenas de dolo eventual diante de um assim chamado perigo patrimonial equivalente ao dano em negócios de

38 Mais recentemente, FRANKE, StraFo 2016, p. 269 e ss.

39 Em tempos mais recentes, BGH NStZ-RR 2013, 75 (76 e s.).

40 Uma avaliação tanto instrutiva quanto amplamente crítica desta jurisprudência com numerosas demonstrações pode ser encontrada em MüKoStGB-Schneider, $\$ 212$ nm. 6 e s.; um tanto mais resumido, SCHROTH, ob. cit. (nota 18), p. 791 e ss.

41 Comparar, nessa medida, a decisão da 4 a Turma Penal eventualmente identificada como "teoria do fim da inibição" em BGHSt 57, 183 = NJW 2012, 1524 (1526 e s.); com outras tendências, por outro lado, BGH NStZ-RR 2012, 369 e s. (4 ${ }^{\text {a }}$ Turma Penal); comparar também BGH NStZ 2014, 35 ( $2^{\text {a }}$ Turma Penal) com notas organizativas de Schiemann; diferenciação sobre a teoria do fim da inibição, cf. SCHROTH, ob. cit. (nota 18), p. 788 e ss.

42 Mais recentemente RISSING-VAN SAAN, ob. cit. (nota 13), p. 504 e ss.; similar também BGH NJW 2012, 1524 (1526 ao final): a teoria do fim da inibição se exaure em uma referência ao §261 StPO.

43 Claramente (sobre infidelidade de crédito) BGHSt 46, 30 = NJW 2000, 2364 (2365 e ss.).

44 Por exemplo, WITTIG, Wirtschaftsstrafrecht, $\$ 6 \mathrm{~nm} .157$ e ss.; TIEDEMANN, Wirtschaftsstrafrecht AT, nm. 336 e ss; sobre erros em modificações delitivas específicas no Direito Penal Econômico, também VOLK, ob. cit. (nota 37), §2 nm. 42. 
risco ${ }^{45}$. Mas a casuística aqui não apenas é muito menos diferenciada do que nos homicídios, mas está intimamente relacionada às peculiaridades da infidelidade patrimonial nos negócios de risco e no perigo patrimonial equivalente ao dano ${ }^{46}$. No que diz respeito a esta última figura jurídica, os princípios também foram transportados para o dolo de prejudicar no estelionato ${ }^{47}$. Mais recentemente, o debate afastou-se dos pressupostos subjetivos em direção a critérios objetivos de restrição em casos de perigo patrimonial equivalente ao dano ${ }^{48}$.

Quando, a seguir, são discutidas questões da determinação processual do dolo dos dirigentes empresariais em relação aos crimes relacionados à empresa cometidos por subordinados, deve-se partir de uma função orientadora da jurisprudência sobre o dolo eventual de matar, na medida em que os princípios ali desenvolvidos se revelarem transponíveis. Naturalmente, a jurisprudência sobre infidelidade patrimonial também será levada em conta, quando materialmente apropriada. Em qualquer caso, não se deve perder de vista que a determinação processual do dolo é um domínio original do juiz criminal, sobre o qual, independentemente dos fatos concretos e de sua prova no processo, são possíveis apenas declarações abstratas muito limitadas ${ }^{49}$.

\subsection{0 elemento cognitivo do dolo}

Para a avaliação do elemento cognitivo do dolo, é crucial verificar quão alto era o risco da prática de crimes relacionados à empresa de um ponto de vista objetivo, isto é, sob a perspectiva de um observador razoável ${ }^{50}$. Isso corresponde ao critério do perigo à vida decorrente de atos violentos na determinação do dolo de matar, que possui normalmente um valor probatório considerável (embora não absoluto). Quando, devido a circunstâncias específicas, deva-se contar, em considerável medida, com o risco de cometimento de delitos pelos subordinados, um dirigente empresarial não pode, normalmente, alegar que não estaria consciente

Ver por exemplo, BGH NJW 1990, 3219 (3220); BGH NJW 2000, 2364 (2365 e s.); BGHSt 47, 148 = NJW 2002, 1211 (1215 e s.).

Análise aprofundada com indicações introdutórias em HILLENKAMP, FS-Maiwald, p. 326.

BGHSt 48, 331 = NJW 2004, 375 (379 e s.); BGH NStZ-RR 2008, 239 e s.

48 Sobre esse desenvolvimento, por exemplo, BECKER, HRRS 2009, p. 334 e ss.; mais recente e introdutório, ENSENBACH, Prognoseschaden bei der Untreue, p. 187 e ss., com outras referências. em tempos recentes, BGH NStZ-RR 2013, 89 (90); sobre a "saturação" do conceito de dolo pelo juiz do fato fala SCHROTH, ob. cit. (nota 18), p. 788. 
desse risco. Meras dúvidas abstratas, para as quais não existe nenhum ponto de referência real, não impedem a afirmação do dolo ${ }^{51}$.

Se, por exemplo, os representantes de vendas obtêm grandes encomendas em um ambiente regional e/ou material em que, como é sabido, isso é praticamente impossível sem o pagamento de propinas, entra em questão a admissão judicial do elemento cognitivo do dolo se o dirigente empresarial afirma que ele não esperava a prática de crimes de corrupção. Entretanto, além da mera atividade comercial em uma região correspondente, provavelmente será necessário exigir indicadores adicionais em relação à conclusão de um negócio específico, porque não é fácil verificar permanentemente todas as transações em determinados países ${ }^{52}$. Se forem estabelecidas metas manifestamente inatingíveis para os subordinados, é natural que o juiz criminal possa concluir, apesar das alegações em contrário, pela existência (no mínimo) do conhecimento da administração sobre a possibilidade de infrações. Indícios de estresse, sobrecarga, repressão ou outras circunstâncias psicológicas normais não formam, nessa medida, um empecilho para a aceitação do elemento cognitivo do dolo ${ }^{53}$. No entanto, uma defesa crível de que o réu tratou de modo extremamente superficial certas questões pode fundamentar um indício contrário à existência do elemento cognitivo do dolo ${ }^{54}$.

$\mathrm{O}$ efeito de perigo à vida manifestado em tiros de pistola, facadas e outros atos de violência é, porém, parte de um conhecimento empírico geral que pode fundamentalmente ser tomado como pressuposto para todo réu mentalmente são ${ }^{55}$. O mesmo não pode ser dito, sem mais, sobre o risco de cometimento de delitos por subordinados em empresas. A esse respeito, o BGH salientou, corretamente, no contexto de casos de Direito Penal patrimonial, que, no caso de eventos complexos e ambíguos, uma avaliação do dolo baseada apenas na situação de risco objetiva é preocupante ${ }^{56}$. A alegação de um dirigente de empresa de que não reconheceu o risco de cometimento de crimes pode, portanto, ser considerada pelo juiz criminal como um indício contrário à prova do dolo, se faltava ao réu uma visão suficiente sobre as unidades de negócio envolvidas que,

52 Nesse sentido, com razão, KUHLEN, NZWiSt 2015, p. 128 contra LG München (Tribunal Regional de Munique), I ZIP 2014, 570 (575) - "Siemens/Neubürger".

53 Compara-se BGH NStZ-RR 2003, 8 e s. Com mais detalhes e outras indicações, MüKoStGB-Schneider, §212, nm. 9.

54 Nesse sentido, FRISCH, ob. cit. (nota 19), p. 558, com outras referências.

55 Ver, por exemplo, BGH NStZ-RR 1996, 323, sobre tiros em pessoas com arma de fogo; NStZ 2004, 201 (202), sobre agitar violentamente uma criança.

56 BGH NJW 2000, 2364 (2365 e s.), com outras referências. 
consequentemente, tornasse plausível um erro de avaliação do risco. Isso deve ser especialmente considerado no caso de um órgão colegiado com vários membros se os delitos são cometidos fora da área de competência de um deles ${ }^{57}$, pelo que o BGH, em sua fundamental "decisão sobre o spray de couro", postulou, para certas constelações de casos, uma obrigação de monitoramento e controle interdepartamental dentro desses órgãos ${ }^{58}$. Se um dirigente nunca trabalhou efetivamente em vendas, ele pode não estar ciente de práticas corruptas em certas regiões do mundo ou segmentos de mercado. Quem formula metas de vendas em relação a determinados departamentos só reconhece um risco relacionado de infrações se os procedimentos e as condições do respectivo departamento lhe forem razoavelmente familiares. Se, de acordo com o caso concreto, houver indicadores confiáveis e fáticos de que um risco objetivamente existente pode não ter sido reconhecido devido à ausência de conhecimento setorial específico ou de ausência de competência do dirigente acusado, isso deve ser discutido pelo juiz no âmbito da valoração probatória e pode sugerir a negativa do elemento cognitivo do dolo. Questões equivalentes se colocam, naturalmente, já para o Ministério Público em um estágio preliminar, quando examina se os fatos averiguados são suficientes para justificar uma acusação contra os dirigentes empresariais.

\subsection{0 componente volitivo}

Se o componente cognitivo do dolo for apurado corretamente, será ainda necessária outra valoração probatória: se o réu, apesar da reconhecida possibilidade de realização do tipo, poderia ter confiado seriamente em sua não ocorrência e, desse modo, agido com culpa consciente ${ }^{59}$. Também aqui o risco objetivo constitui o ponto de partida decisivo, razão pela qual o BGH, no contexto de homicídios, valora a elevada e explícita periculosidade à vida do comportamento do agressor como o indicador decisivo de ambos os elementos do dolo ${ }^{60}$. Também em casos de dolo relacionados ao perigo ao patrimônio equiparado a dano, a extensão e a obviedade da situação de risco são indícios centrais no que se refere

57 Compare-se, sobre os limites da competência como limites à imputação de conhecimento à pessoa jurídica, WELLER, ob. cit. (nota 5), p. 406 e s.

58 Sobre isso, RÖNNAU, GmbHG, §82 nm. 33, com outras referências.

59 Sobre a exigência do exame separado baseado em fatos dos dois componentes do dolo, v. recentemente, por exemplo, BGH NStZ-RR 2016, 204 ao final.

60 Compare-se, recentemente, BGH NStZ-RR 2016, 204; NJW 2016, 1970 (1971); outras indicações em MüKoStGB-Schneider, $\$ 212 \mathrm{~nm}$. 65, nota de rodapé 231; v. também RISSING-VAN SAAN, ob. cit. (nota 13), p. 503. 
aos dois elementos do dolo ${ }^{61}$. Isso significa, no presente contexto, que a conclusão judicial sobre o dolo eventual do dirigente da empresa é igualmente possível, também sob o ponto de vista da vontade, em regra, se na situação concreta o risco de cometimento de crimes relacionados à empresa pelos empregados era claramente extremamente alto. Em geral, a alegação de que o réu não tinha conhecimento desse risco ou confiava na ausência de sua realização não impede, por si, a determinação do dolo eventual. Por outro lado, indícios contrários ao dolo devem ser apreciados pelo juiz criminal, sobretudo ao examinar o componente volitivo, sempre que existam indicações plausíveis, faticamente embasadas e não meramente vagas, para a confiança do acusado na ausência de realização do tipo, pelo que, mesmo que o risco de realização do tipo seja, do ponto de vista objetivo, particularmente alto, a necessária apreciação global não pode ser completamente omitida ${ }^{62}$. Como os contextos nos crimes econômicos são geralmente mais complexos e ambíguos do que em atos de violência perigosos à vida (vide Seção 2.2, supra), é especialmente importante advertir contra uma conclusão irrefletida sobre o consentimento subjetivo do acusado somente com base na situação de risco objetiva ${ }^{63}$.

A esse respeito, o $\mathrm{BGH}$ exige, além da consideração de fatores objetivos de risco, também fundamentalmente a compreensão dos motivos da conduta do acusado $^{64}$, sua personalidade ${ }^{65}$ e seu comportamento posterior ao fato ${ }^{66}$. Em princípio deve ser levada em conta, portanto, a atitude do dirigente acusado até aquele momento em relação às infrações ou aos seus esforços para evitá-las em situações anteriores ${ }^{67}$. Além disso, tentativas subsequentes de esclarecer o evento podem, sob certas circunstâncias, constituir um indício contra a admissão do dolo eventual. No entanto, esses critérios derivam principalmente de decisões que têm por objeto homicídios particularmente espontâneos e passionais (sobretudo diante de crianças pequenas) ${ }^{68}$. Uma transposição apropriada para os casos

BGH NJW 2002, 1211 (1216); NJW 2004, 375 (379 in fine).

62 V., recentemente, BGH NJW 2016, 1970 (1971) com outras referências; compare-se também BGH NStZ-RR 2008, 239 (240); RISSING-VAN SAAN, ob. cit. (nota 13), p. 503; MüKoStGB-Schneider, §212 nm. 22: nenhum "manejo sistemático"; mais aprofundado e com exemplos, SCHNEIDER, FS-Dahs, p. 190 e ss.

64 BGH NStZ 2011, 338 (339), com outras referências.

65 BGH NStZ-RR 2012, 369 (370), com outras referências.

66 BGH NStZ 2007, 331 (332), com outras referências.

67 Compare-se, sobre isso, BGH NStZ 1988, 175; v. também (sobre o dolo na lesão corporal) BGH NStZ 2004, 201 (202) com anotações críticas de Schneider; ademais, FRISCH, ob. cit. (nota 19), p. 557.

68 Avaliação detalhada e crítica dessa jurisprudência, com numerosas indicações, em MüKoStGB-Schneider, \$212 nm. 35 e ss. 
da criminalidade econômica é, na melhor das hipóteses, muito restrita, uma vez que - especialmente o critério frequentemente criticado do ponto de vista do dolo nos casos de homicídio do comportamento passional/irrefletido e espontâneo ${ }^{69}-$, frequentemente, não desempenhará um papel comparativamente grande no comportamento dos dirigentes empresariais. De todo modo, é duvidoso em que medida as circunstâncias mencionadas devem servir de fundamento para uma confiança séria e faticamente embasada do acusado na ausência do cometimento do delito reconhecida como possível ${ }^{70}$. Os motivos do réu podem fornecer indícios, em primeiro lugar, quando a realização do tipo é, de seu ponto de vista, obviamente contrária ao seu interesse ${ }^{71}$. Além disso, a falta de proveito próprio derivada da prática pode ser um fator contrário ao dolo na valoração probatória ${ }^{72}$. No entanto, um interesse pessoal indireto qualquer deve ser levado em conta, como sucede, por exemplo, se os pagamentos de bônus forem devidos quando as metas corporativas forem atingidas.

Como não basta uma confiança vaga e não baseada em fatos na não realização da conduta típica que, todavia, foi reconhecida como possível, é de particular importância a controlabilidade do risco ${ }^{73}$. No caso de riscos incontroláveis, na visão do $\mathrm{BGH}$, a conclusão sobre a aprovação da realização do risco é frequentemente suposta ${ }^{74}$. Sobretudo, os sistemas de conformidade (compliance) podem ser adequados para evitar a prática de crimes na empresa ${ }^{75}$. Ausente sua instituição, apesar do risco objetivamente elevado de cometimento de crimes, isso pode sugerir a existência de dolo eventual ${ }^{76}$. Porque aqueles que não tomam nenhuma medida, apesar de evidências robustas de um ambiente de negócios criminógeno, expressam com isso que, ao fim e ao cabo, abandonam a realização

69 Compare-se, por exemplo, BGH NStZ 2009, 629 (630), com outras referências.

70 Criticado com razão em MüKoStGB-Schneider, \$212 nm. 38.

71 Compare-se, sobre isso, BGH NStZ-RR 2006, 317 (318); BGH decisão de 29.9.1999 - 2 StR 349/99 em ALTVATER, NStZ 2000, 18 (19); FRISCH, ob. cit. (nota 19), p. 560.

72 BGH NJW 1990, 3219 (3220).

73 Aplicável a este respeito BGH NJW 1990, 3219 (3220); compare-se também (sobre o dolo concernente ao perigo de dano patrimonial), VOLK, ob. cit. (nota 37 ), $\$ 2 \mathrm{~nm} .51$ e ss.

74 BGH NJW 2002, 1211 (1216); em geral, sobre o significado indiciário das medidas de prevenção, FRISCH, ob. cit. (nota 19), p. 538, com outras referências; ademais HILLENKAMP, ob. cit. (nota 34), p. 351 e ss.

75 Recentemente, sobre a justificativa e os limites de um dever de conformidade, KUHLEN, NZWiSt 2015, p. 126 e ss. e passim, com outras referências.

76 Ver também KUHLEN, NZWiSt 2015, p. 126, nota de rodapé 82; em geral sobre a omissão de possíveis medidas de prevenção como indício, HILLENKAMP, ob. cit. (nota 34), p. 365 e s. 
do risco ao acaso ${ }^{77}$. Por outro lado, um sistema de conformidade instalado e efetivo, com a instituição de deveres de comunicação dos empregados responsáveis aos dirigentes da empresa ${ }^{78}$, pode ser um indício contra a admissão do dolo eventual porque indica uma base fática concreta e confiável que permite supor que, em princípio, o risco inerente ao cometimento de delitos seria controlável ${ }^{79}$. No entanto, quando a conformidade só ocorre "no papel" ou se esgota em uma mera fachada, ela não é levada em consideração como indício excludente do dolo, porque, nesse ambiente, o dirigente não pode confiar que é capaz de controlar o perigo por meio de um departamento de conformidade ineficaz e instituído apenas pro forma. Por outro lado, a explicação crível de ter superestimado a capacidade do sistema de conformidade pode, em algumas circunstâncias, justificar a conclusão pela falta de dolo ${ }^{80}$. Para isso, deve sempre ser verificado se os esforços de controle e evitação das condutas realmente produzem uma confiança do agente na não realização do tipo ou se simplesmente reduzem um risco elevado ${ }^{81}$.

Finalmente, revela-se ambivalente, no contexto da determinação do dolo, a avaliação de medidas de impedimento informacional diante de âmbitos empresariais potencialmente criminógenos. Dependendo da estrutura organizacional e da distribuição de competências, a alegação do réu de que ele não tinha conhecimento de determinadas circunstâncias de risco relevantes pode ser inteiramente crível e plausível, fundamentando, assim, a conclusão pela ausência já do componente cognitivo do dolo (ver Seção 2.2, supra). Pelo contrário, uma falha em se ocupar de eventos potencialmente relevantes do ponto de vista jurídico-penal, ignorando advertências e indicações concretas, pode justificar a conclusão pela indiferença e pela ausência de domínio do risco e, assim, contribuir para a afirmação do dolo eventual. Aqui se evidencia como o processo penal mitiga o problema da preferência pela indiferença em relação aos fatos, um problema aparentemente fundado na concepção psicológica em sentido jurídico-material. Qualquer pessoa que, apesar de indícios óbvios de cometimento de delitos, permaneça inativa e possivelmente até se recuse a seguir indicações recebidas, di-

77 Além disso (em conexão com a punibilidade de acordo com os $\S \S 263$, 263a StGB no chamado processo "WAP-Billing"), WEGNER, NStZ 2016, p. 458.

78 Sobre a possibilidade e os limites da delegação dos deveres de conformidade, ZIMMERMANN, Strafbarkeitsrisiken durch Compliance, p. 171 e ss.

79 Sobre a interação entre compliance e o $\$ 130$ OWiG (possível exclusão típica ou consideração no contexto do cálculo da multa), comparar a síntese de RÖNNAU, ZGR 45, p. 293 e s.

80 Em geral, sobre o erro de avaliação do perigo como indício relevante para o dolo, FRISCH, ob. cit. (nota 19), p. 556 e s., com outras referências.

81 Compare-se, sob esse aspecto, HILLENKAMP, ob. cit. (nota 34), p. 359. 
ficilmente poderá alegar com sucesso no processo penal, diante de indícios objetivos robustos, que não reconheceu os perigos envolvidos ou que, pelo menos, não assentiu com sua realização. Quem, por outro lado, lida com tais eventos e toma contramedidas sérias, gera indícios de uma confiança baseada em fatos na controlabilidade do risco reconhecido, o que pode produzir um efeito contrário ao dolo na avaliação judicial.

\section{Responsabilidade de acordo com $0 \$ 130$ OWiG}

O §130 I OWiG 82 compreende, como destinatário da norma, o "titular de um estabelecimento ou empresa" e sanciona a omissão de medidas de supervisão "necessárias para evitar infrações de deveres no estabelecimento ou na empresa, os quais recaem sobre o titular e cuja infração seja punível com prisão ou multa". O dispositivo é uma "norma de conformidade nata" ("geborene Compliance-Norm"), que, em conjunto com o $\$ 9 \mathrm{OWiG}$, estabelece a responsabilidade dos órgãos de gestão (em lugar do titular do estabelecimento ou da empresa, legalmente apontado) pelas medidas de supervisão exigidas e, junto com o $\S 30$ da mesma lei, pode ter por consequência a imposição de multas elevadas contra a empresa. Embora os detalhes da regulamentação não possam ser aqui descritos com maior profundidade, uma rápida indicação é relevante no nosso contexto, porque o dispositivo é aplicável já nos casos de (mera) omissão culposa de adoção de medida de supervisão, desde que fosse necessária e razoável e sempre que a infração "tivesse sido evitada ou consideravelmente dificultada pela supervisão adequada".

Para os órgãos de persecução penal, trata-se, portanto, de uma ferramenta bastante eficaz, tendo em vista as possibilidades de sanções financeiras disponíveis nos casos em que a prova do dolo eventual não pareça suficiente e não exista - como é frequente no Direito Penal Econômico - a possibilidade de punição por culpa. E é eficaz, ademais, porque a infração exigida na lei, ou seja, o crime ou a contraordenação cometido por um empregado, é concebida como uma condição objetiva de punibilidade, de modo que, relativamente a ela, nem mesmo é necessária uma conduta culpável daqueles obrigados a adotar as medidas de supervisão. 


\section{Conclusão}

Uma contribuição criminalmente relevante dos dirigentes empresariais em crimes dolosos relacionados à empresa cometidos por subordinados pressupõe pelo menos o dolo eventual quanto ao cometimento de tais crimes. Isso exige, do ponto de vista jurídico-material, que o agente leve seriamente em conta a possibilidade da prática de tais crimes e concorde com seu cometimento ou com eles consinta (em sentido jurídico). Por outro lado, se o dirigente confia sinceramente na não ocorrência do risco por ele reconhecido, não haverá dolo, independentemente de essa confiança, efetivamente existente na mente do perpetrador, ser produto de repressão, indiferença ou simples desconsideração de sinais óbvios. Do ponto de vista processual, a conclusão judicial sobre a admissão do dolo eventual se mostrará possível e, portanto, fático-juridicamente autorizada se, objetivamente, houver um risco significativo de cometimento de crimes e não houver indícios de que eles foram mal compreendidos ou desaprovados. Nesse sentido, devem ser levados em consideração, como indícios contrários ao dolo, sobretudo medidas de conformidade ou outros instrumentos eficazes para o controle de riscos, dos quais se pode derivar uma confiança faticamente fundada do dirigente empresarial na não ocorrência do evento criminoso. Quando não houver prova do dolo, deve-se observar, na prática, especialmente o disposto no $\$ 130$ OWiG, que autoriza a aplicação de sanções financeiras substanciais contra a empresa nos casos de omissão culposa de medidas de supervisão.

\section{Referências}

ACHENBACH, Hans. Zurechnung unternehmensbezogenen Handelns. In: ACHENBACH, Hans; RANSIEK, Andreas; RÖNNAU, Thomas (Hrsg.). Handbuch Wirtschaftsstrafecht. 4. Auflage. Heidelberg: C.F. Müller, 2015.

ALTVATER, Gerhard. Rechtsprechung des BGH zu den Tötungsdelikten. Neue Zeitschrift für Strafrecht, [s.I.], p. 18-24, 2000.

AMBOS, Kai. Internationales Strafrecht: Strafanwendungsrecht Völkerstrafrecht - Europäisches Strafrecht - Rechtshilfe. 4. Auflage. München: C.H. Beck, 2014.

BECKER, Christian. Paradigmenwechsel in der Schadensdogmatik oder "Viel Lärm um nichts"? Zur aktuellen Kontroverse um die sog. "schadensgleiche Vermögensgefährdung". Onlinezeitschrift für Höchstrichterliche Rechtsprechung zum Strafrecht, [s.I.], v. 10, n. 8/9, p. 334-340, 2009. 
BUCK-HEEB, Petra. §2. In: HAUSCHKA, Christoph E.; MOOSMAYER, Klaus; LÖSLER, Thomas (Hrsg.). Corporate Compliance: Handbuch der Haftungsvermeidung im Unternehmen. 3. Auflage. München: C.H. Beck, 2016.

BÜLTE, Jens. Vorgesetztenverantwortlichkeit im Strafrecht. Baden-Baden:

Nomos Verlag, 2015.

BUNG, Jochen. Wissen und Wollen im Strafrecht: zur Theorie und Dogmatik des subjektiven Tatbestands. Frankfurt am Main: Klostermann, 2009.

ENSENBACH, Kai. Prognoseschaden bei der Untreue: vom "Gefährdungsschaden" zur wirtschaftlichen Prognose anhand der Sicherheitslösung. Tübingen: Mohr Siebeck, 2016.

FISCHER, Thomas. Strafgesetzbuch. 63. Auflage. München: C.H. Beck, 2016.

FRANKE, Ulrich. Die Beweiswürdigung in der Revision - insbesondere die Abgrenzung von bedingtem Vorsatz zur Fahrlässigkeit. Strafverteidiger Forum, [s.I.], p. 269-274, 2016.

FRISCH, Wolfgang. Gegenwartsprobleme des Vorsatzbegriffs und der Vorsatzfeststellung am Beispiel der AIDS-Diskussion. In: GEPPERT, Klaus (Hrsg.). Gedächtnisschrift für Karlheinz Meyer. Berlin: De Gruyter, 1990. p. 533-566.

FRISCH, Wolfgang. Vorsatz und Risiko. Köln: Heymann, 1983.

GAEDE, Karsten. Auf dem Weg zum potentiellen Vorsatz? Problematik und Berechtigung der zunehmenden Tendenzen zur normativen Relativierung des Vorsatzerfordernisses. Zeitschrift für die Gesamte Strafrechtswissenschaft, Berlin, v. 121, n. 2, p. 239-280, 2009. DOI: 10.1515/ZSTW.2009.239.

GAEDE, Karsten. §15. In: MATT, Holger; RENZIKOWSKI, Joachim (Hrsg.). Strafgesetzbuch: Kommentar. München: Vahlen, 2013.

HASSEMER, Winfried. Kennzeichen des Vorsatzes. In: DORNSEIFER, Gerhard (Hrsg.). Gedächtnisschrift für Armin Kaufmann. Köln: Heymann, 1984. p. 289-309.

HERZBERG, Rolf Dietrich. Die Abgrenzung von Vorsatz und bewußter Fahrlässigkeit - ein Problem des objektiven Tatbestandes. Juristische Schulung, [s.I.], v. 26, p. 249-262, 1986.

HEß, Josef. Steuerstrafrechtliche Aspekte bei der Manipulation von PkwSchadstoffmessungen. Zeitschrift für Wirtschafts- und Steuerstrafrecht, [s.I.], n. 6, p. 212-215, 2016.

HILLENKAMP, Thomas. 32 Probleme aus dem Strafrecht: Allgemeiner Teil. 14. Auflage. München: Verlag Franz Vahlen, 2012. 
HILLENKAMP, Thomas. Dolus eventualis und Vermeidewille. In: DORNSEIFER, Gerhard (Hrsg.). Gedächtnisschrift für Armin Kaufmann. Köln: Heymann, 1984. p. 351-369.

HILLENKAMP, Thomas. Zur Kongruenz von objektivem und subjektivem Tatbestand der Untreue. In: BLOY, René (Hrsg.). Gerechte Strafe und legitimes Strafrecht: Festschrift für Manfred Maiwald zum 75. Geburtstag. Berlin: Duncker \& Humblot, 2010. p. 323 ss.

HRUSCHKA, Joachim. Über Schwierigkeiten mit dem Beweis des Vorsatzes. In: GÖSSEL, Karl Heinz (Hrsg.). Strafverfahren im Rechtsstaat: Festschrift für Theodor Kleinknecht zum 75. Geburtstag am 18. August 1985. München: Beck, 1985. p. 191-202.

ISFEN, Osman. Mehr Schein als Sein - die VW-Abgasaffäre aus strafrechtlicher Sicht. Juristische Arbeitsblätter, [s.I.], p. 1-6, 2016.

JAKOBS, Günther. Gleichgültigkeit als dolus indirectus. Zeitschrift für die Gesamte Strafrechtswissenschaft, Berlin, v. 114, n. 3, p. 584-599, 2002. DOI: 10.1515/ zstw.2002.114.3.584.

JOECKS, Wolfgang. §16. In: HEINTSCHEL-HEINEGG, Bernd von (Herausgeber). Münchener Kommentar zum Strafgesetzbuch. 2. Auflage. München: C.H. Beck, v. 1, 2011.

KINDHÄUSER, Urs. Gleichgültigkeit als Vorsatz? In: ARNOLD, Jörg (Hrsg.). Menschengerechtes Strafrecht: Festschrift für Albin Eser zum 70. Geburtstag. München: Beck, 2005. p. 345-358.

KUHLEN, Lothar. Zum Verhältnis von strafrechtlicher und zivilrechtlicher Haftung für Compliance-Mängel, Teil 1. Neue Zeitschrift für Wirtschafts-, Steuer- und Unternehmensstrafrecht, [s.I.], v. 4, n. 4, p. 121-129, 2015.

LUBAN, David. Contrived ignorance. Georgetown Law Journal, [s.I.], v. 87, p. 957-980, 1999.

MARCUS, Jonathan L. Model Penal Code Section 2.02(7) and willful blindness. Yale Law Journal, [s.I.], v. 102, p. 2231-2257, 1993.

MIEBACH, Klaus. \$261. In: SCHNEIDER, Hartmut (Hrsg.). Münchener Kommentar zur Strafprozessordnung. München: C.H. Beck, v. 2, 2016.

PUPPE, Ingeborg. \$15. In: KINDHÄUSER, Urs; NEUMANN, Ulfrid; PAEFFGEN, Hans-Ulrich. Strafgesetzbuch. 4. Auflage. Baden-Baden: Nomos Verlag, 2013.

PUPPE, Ingeborg. Der Vorstellungsinhalt des dolus eventualis. Zeitschrift für die Gesamte Strafrechtswissenschaft, Berlin, v. 103, n. 1, p. 1-42, 1991. DOI: 10.1515/zstw.1991.103.1.1. 
RISSING-VAN SAAN, Ruth. Der bedingte Tötungsvorsatz und die Hemmschwellentheorie des Bundesgerichtshofs. In: GEISLER, Claudius (Hrsg.). Festschrift für Klaus Geppert zum 70. Geburtstag am 10. März 2011. Berlin: De Gruyter, 2011. p. 497-518.

ROGALL, Klaus. \$130. In: SENGE, Lothar (Hrsg.). Karlsruher Kommentar zum Gesetz über Ordnungswidrigkeiten. 4. Auflage. München: C.H. Beck, 2014.

RÖNNAU, Thomas. Einrichtung "schwarzer" (Schmiergeld-) Kassen in der Privatwirtschaft - eine strafbare Untreue? In: SIEBER, Ulrich (Hrsg.). Strafrecht und Wirtschaftsstrafrecht: Dogmatik, Rechtsvergleich, Rechtstatsachen; Festschrift für Klaus Tiedemann zum 70. Geburtstag. Köln: Heymann, 2008. p. 713-736.

RÖNNAU, Thomas. Grundwissen - Strafrecht: Vorsatz. Juristische Schulung, [s.I.], v. 50, n. 8, p. 675-678, 2010.

RÖNNAU, Thomas. Haftung für unterlassene Aufsicht nach $\S 130 \mathrm{OWiG}$ und strafrechtlicher (Drittempfänger-)Verfall gemäß $§ 73$ Abs. 3 StGB - zwei bedeutsame Bedrohungsszenarien für Unternehmen. Zeitschrift für Unternehmens- und Gesellschaftsrecht, [s.I.], v. 45, n. 2/3, p. 384-413, 2016. DOI: 10.1515/zgr-2016-0277.

RÖNNAU, Thomas; TIEDEMANN, Klaus. §82. In: SCHOLZ, Franz (Hrsg). GmbHG: Kommentar. 11. Auflage. Köln: Verlag Dr. Otto Schmidt, 2015.

ROTSCH, Thomas. §4 (Originäre strafrechtliche Verantwortlichkeit). In: ROTSCH, Thomas (Hrsg.). Criminal Compliance. Baden-Baden: Nomos Verlag, 2015. p. 142 ss.

ROTSCH, Thomas. Criminal Compliance. In: ACHENBACH, Hans; RANSIEK, Andreas; RÖNNAU, Thomas (Hrsg.). Handbuch Wirtschaftsstrafecht. 4. Auflage. Heidelberg: C.F. Müller, 2015.

ROXIN, Claus. Strafrecht. Allgemeiner Teil: Grundlagen, der Aufbau der Verbrechenslehre. 4. Auflage. München: C.H. Beck, v. I, 2006.

ROXIN, Claus. Zur Normativierung des dolus eventualis und zur Lehre von der Vorsatzgefahr. In: ROGALL, Klaus (Hrsg.). Festschrift für Hans-Joachim Rudolphi zum 70. Geburtstag. Neuwied: Luchterhand, 2004. p. 243-257. (= Sobre a normativização do dolo eventual e a doutrina do perigo doloso. Trad. Eduardo Viana. Revista de Estudos Criminais, Porto Alegre, v. 19, n. 79, p. 7-27, 2020.)

SAMSON, Erich. Absicht und direkter Vorsatz im Strafrecht. Juristische Arbeitsblätter, [s.I.], p. 449-454, 1989.

SCHALL, Hero. Geschäftsherrenhaftung und Mobbing. In: HEGER, Martin; KELKER, Brigitte; SCHRAMM, Edward (Hrsg.). Festschrift für Kristian Kühl zum 70. Geburtstag. München: Beck, 2014. p. 417-432. 
SCHEMMEL, Alexander; KIRCH-HEIM, Claudio. "Willful Blindness" im Wirtschaftsstrafrecht - Kann gewollte Unwissenheit vor Strafe schützen? Corporate Compliance Zeitschrift, [s.I.], v. 1, n.8, p. 96-100, 2008.

SCHNEIDER, Hartmut. \$212. In: SANDER, Günther M. (Hrsg.). Münchener Kommentar zum Strafgesetzbuch. 2. Auflage. München: C.H. Beck, v. 4, 2012.

SCHNEIDER, Hartmut. Zur Annahme von Tötungsvorsatz bei Abgabe von Schüssen. In: WIDMAIER, Gunter; LESCH, Heiko; MÜSSIG, Bernd; WALLAU, Rochus (Hrsg.). Festschrift für Hans Dahs. Köln: Verlag Dr. Otto Schmidt, 2005, p. 189-206.

SCHROTH, Ulrich. Der bedingte Tötungsvorsatz im Spiegel der Rechtsprechung. In: SCHÖCH, Heinz (Hrsg.). Strafverteidigung, Revision und die gesamten Strafrechtswissenschaften: Festschrift für Gunter Widmaier zum 70. Geburtstag. Köln: Heymann, 2008. p. 779-799.

SCHROTH, Ulrich. Vorsatz als Aneignung der unrechtskonstituierenden Merkmale. Frankfurt am Main: Lang, 1994.

SCHÜNEMANN, Bernd. Vom philologischen zum typologischen Vorsatzbegriff. In: WEIGEND, Thomas; KÜPPER, Georg (Hrsg.). Festschrift für Hans Joachim Hirsch zum 70.Geburtstag am 11.April 1999. Berlin: De Gruyter, 1999. p. 363-378. (= Do conceito filológico ao conceito tipológico de dolo. Trad. Luís Greco e Ana Cláudia Grossi. In: SCHÜNEMANN, Bernd. Estudos de direito penal, direito processual penal e filosofia do direito. São Paulo: Marcial Pons, 2013. p. 127-141.)

SPINDLER, Gerald. Unternehmensorganisationspflichten: zivilrechtliche und öffentlich-rechtliche Regelungskonzepte. Köln: Heymann, 2001.

TIEDEMANN, Klaus. Wirtschaftsstrafrecht: Einführung und Allgemeiner Teil mit wichtigen Rechtstexten. 4. Auflage. München: Vahlen, 2014.

VOGEL, Joachim. §15. In: LAUFHÜTTE, Heinrich Wilhelm; RISSING-VAN SAAN, Ruth; TIEDEMANN, Klaus. Leipziger Kommentar Strafgesetzbuch. 12. Auflage. Berlin: De Gruyter, v. 1, 2007.

VOGEL, Joachim. Normativierung und Objektivierung des Vorsatzes? Goltdammer's Archiv für Strafrecht, [s.I.], v. 153, p. 386-389, 2006.

VOLK, Klaus. §2 (Der Allgemeine Teil des Wirtschaftsstrafrechts). In: VOLK, Klaus (Hrsg.). Münchener Anwaltshandbuch. Verteidigung in Wirtschaftsund Steuerstrafsachen. 2. Auflage. München: C.H. Beck, 2014. p. 38 ss.

WEGNER, Kilian. Betrugsstrafbarkeit bei Missbrauch des "WAP-Billing"-Verfahrens. Neue Zeitschrift für Strafrecht, [s.I.], p. 455-460, 2016. 
WELLER, Marc-Philippe. Wissenszurechnung in internationalen

Unternehmensstrafverfahren. Zeitschrift für Unternehmens- und Gesellschaftsrecht, [s.I.], v. 45, n. 2/3, p. 384-413, 2016. DOI: 10.1515/zgr-2016-0384.

WITTIG, Petra. Wirtschaftsstrafrecht. 3. Auflage. München: C.H. Beck, 2014.

ZIMMERMANN, Susanne Annette. Strafbarkeitsrisiken durch Compliance:

Auswirkungen von Compliance-Regelungen auf das Wirtschaftsstrafrecht. Berlin:

Duncker \& Humblot, 2014.

\section{Sobre os autores:}

Thomas Rönnau | E-mail: thomas.roennau@law-school.de

Doutor em Direito (Uni-Kiel/Alemanha). Professor titular de Direito Penal, Direito Penal Econômico e Direito Processual Penal (Bucerius Law School/Alemanha).

Christian Becker | E-mail: cbecker@europa-uni.de

Doutor em Direito (Bucerius Law School/Alemanha). Professor titular de Direito Penal, Direito Processual Penal e Filosofia do Direito (Europa-Universität Viadrina/Alemanha).

Recebimento: 24.11 .2021

Aprovação: 26.12 .2021

Artigo convidado 